\title{
Zoonoses in the South
}

\author{
By J. D. MARTIN, M.D., M.P.H.
}

$\mathrm{T}$ HE World Health Organization lists 87 diseases of lower animals transmissible to man (1). Of these, 49 occur in the southern United States (see table). As man's knowledge increases, still other zoonoses will probably be recognized, classified, and studied. The epidemiological concept of animal-to-man transmission is already broadening to include the concept of man to animal to man transmissibility of disease. The zoonoses, therefore, are of importance in human health and disease, and we need to know more concerning them.

\section{Early Knowledge}

Man's knowledge of some of the zoonoses dates back to antiquity, and control measures antedate recognition of the infectious nature of these diseases by hundreds of years. Although the exact cause of bacterial, rickettsial, and viral infections remained unknown to the ancients, they nevertheless developed a remarkable amount of useful information, including accurate descriptions of clinical entities and much detailed epidemiological information.

A pestilence associated with the presence of multitudes of "mice," probably bubonic plague, is mentioned in the Bible. Another disease, which could have been anthrax, is recorded in the Bible as destroying all the beasts-horses, asses, oxen, camels, and sheep-in the time of Moses.

Rabies was one of the first recognized dis-

Dr. Martin is chief, section of epidemiology, division of preventive medicine, Louisiana State Department of Health, New Orleans, La. This is a modified version of a paper presented at the 1955 meeting of the Southern Branch of the American Public Health Association. eases. Kelser (2) says, "Plutarch asserted that, according to Athenodorus, it was observed in mankind in the days of the Aesculapaidae, the descendants of Aesculapius, the god of medicine. Kelser also quotes Aristotle in the fourth century B. C. as writing that "dogs suffer from madness which puts them in a state of fury, and all animals which they bite when in this condition become also attacked with madness."

Tsutsugamushi fever, or mite typhus, is believed by Williams (3) to have been recognized as an entity since the 6th century A. D. Blake and co-workers (4) believe that it afflicted the natives of south China in the 16th century.

Epidemics of louseborne typhus probably occurred in any civilization whenever people lived under crowded, insanitary conditions. "In 1083 an epidemic occurred in Italy which, probably, was typhus. A few years later in 1106, another epidemic, apparently of the same disease, occurred in Bohemia. In both of these epidemics the outbreak followed famine" (5).

\section{Current Status}

In recent years much has been accomplished in the prevention and control of respiratory and enteric diseases. It is now time to strengthen, through adequate maintenance and surveillance programs, the gains that have been made against these diseases. It is time also to attack forcefully the zoonoses because of their increasing importance to health and economy.

During the period 1944-55, seven zoonosesbrucellosis, rabies, ringworm, salmonellosis, staphylococcosis, streptococcicosis, and tuberculosis were reported in all of the southern States and the District of Columbia. In the District of Columbia, however, human rabies ( 2 cases) 
was last reported in 1944 and dog rabies (1 case) in 1950 . Psittacosis was reported in all of these States but Missouri. Leishmaniasis was reported only in Florida and trypanosomiasis, only in Texas.

Holle states that the first two cases of American trypanosomiasis in this country were reported from Texas in $1955(6)$. The etiological agent Trypanosoma cruzi was demonstrated in the cerebrospinal fluid of the second reported case. Six species of Triatoma in Texas have been found to be naturally infected with cruzi.

Forty-five of the forty-nine zoonoses known to occur in the south have been reported in Texas, according to a personal communication from the State epidemiologist and the Livestock Sanitary Commission. When the survey questionnaires were returned, rickettsialpox, leishmaniasis, glanders, and ratbite fever were not reported as occurring in Texas. However, Griffith and McNaughton ( $y$ ) published a report of the occurrence of ratbite fever in Texas. Therefore, 46 of the 49 zoonoses actually occurred in Texas.

Foot-and-mouth disease has not occurred in the United States since 1928. Both Louisiana and Texas have recently been exposed to the threat of this disease, however, by the importation of a herd of Charolais cattle smuggled from Mexico into Louisiana through Texas. This stresses the need for constant surveillance against the importation of exotic diseases.

$Q$ fever has been reported in Mississippi, North Carolina, Texas, Louisiana, and Virginia ; rickettsialpox in Maryland, Mississippi, and Virginia.

Many wild animals are infected with, or are carriers of, infectious agents capable of causing disease in man. Fortunately, man's contact with these animals is so infrequent, or so casual, that it is only occasionally that human infections occur. It is good that this is so because many of the diseases of the lower animals are fatal to man.

\section{Plague}

Sylvatic plague occurs in at least 38 species of rodents in 14 States (8). Important species are: ground squirrels, wood rats, white-tailed prairie dogs, chipmunks, and marmots. The disease is present among the rodents in the States on the plains east of the Rocky Mountains as well as in the States west of the Great Divide. The importance of sylvatic plague as a reservoir of human disease needs continuous investigation.

Murine plague is not an important disease in the United States at this time. The risk of infection spreading through ports and coastal cities must not be overlooked, however. A ship's docking and permitting infected rats to escape to the mainland is prevented only through constant vigilance and control.

Bubonic plague is the most common type of this infection in man-giving rise to about 75 percent of reported cases. The case fatality rate ranges from 50 to 90 percent. Epidemics in man always include a small number of cases of septicemia and secondary plague pneumonia. By aerogenic transfer these cases give rise to other cases of pneumonic plague. Pneumonic infections usually end in death. Seventeen human cases of plague have been reported in the United States since 1925 (8). Fortunately, the vectors of this disease have not had cause, except occasionally, to desert their rodent hosts for man. We must be constantly alert to the possibility of this occurrence, however.

\section{Tularemia}

Tularemia, a disease caused by a bacterium closely related to the bacillus which causes plague, has been reported in all the southern States except Alabama and Missouri. East of the Mississippi the common belief is that most cases in humans are contracted from the handling of infected rabbits. Of late, more cases associated with insect bites, particularly tick bites, have been found. Natural infection occurs in sheep and deer as well as in rodents such as ground squirrels, hares, and rabbits, and in certain wild birds, particularly quail and grouse.

\section{Yellow Fever}

Yellow fever, which ravaged Louisiana almost annually from its colonization until 1905, has not been reported in the southern States since that time. This pestilential disease is one that must be kept under constant surveillance, however, and mechanisms to prevent its 
entering this country need to be perfected and maintained. Jungle yellow fever is gradually moving northward from South America. It has progressed from the jungles of northern
South America through Central America into northern Honduras.

In 1907, Carroll (9) estimated that yellow fever had caused 100,000 deaths in the United

Zoonoses reported in the southern United States, by State, 1944-55 ${ }^{1}$

Amebic dysentery

Anthrax

Arthropod-borne virus

St. Louis encephalitis -1.0
Eastern equine encephalomyelitis

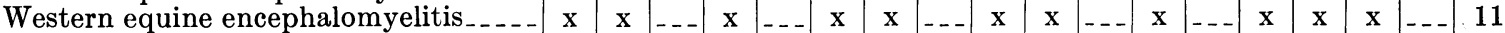

Louping-ill infections

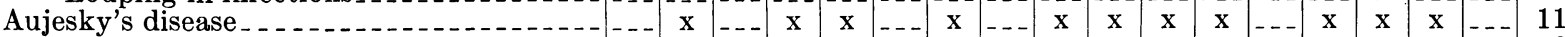

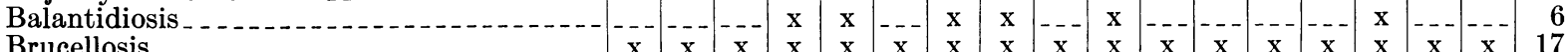

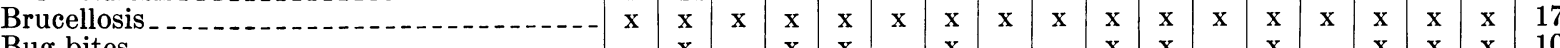

Bug bites
Cestode diseases

Chicken-mite itch__.

Cowpox

Diphtheria_.

Endemic (murine) typhus...

Epizootic lymphangitis _ _...

Equine infectious anemia_...

Erysipeloid.......

Flea bites...........

Glanders

Leishmaniasis

Listeriasis

Lymphocytic choriomeningitis

Myiasis
Nematode diseases

Nematode diseases
Newcastle disease $\ldots$

Ovine pustular dermatitis _...

Pasteurellosis

Pseudotuberculosis

Psittacosis (ornithosis)

Q fever......

Rabies

Ratbite fever...

Relapsing fever

Rickettsialpox

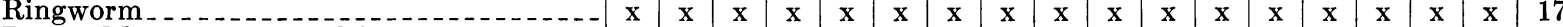

$\begin{array}{ll}\text { Rocky Mountain spotted fever } & \\ \text { Salmonellosis_. }\end{array}$

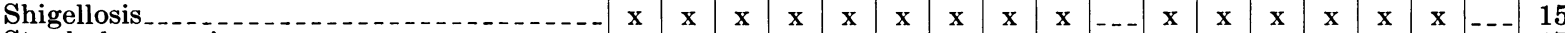

Staphylococcosis.

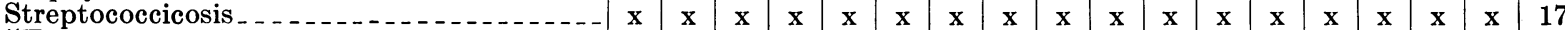

"Tongue worm"

Trypanosomiasis

Tuberculosis

Tularemia

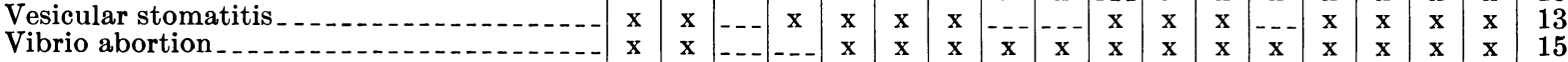

1 Information obtained by questionnaire sent to State departments of health and agriculture. 
States since 1793. Of this number, 40,000 occurred in Louisiana where, in 1905, in the final epidemic, 900 of the 8,000 persons who developed the disease died. Yellow fever is endemic in the jungles of South and Central America, especially in the rain forests. It is also endemic in Africa (10) from the West Coast, south of the Sahara desert, through the Belgian Congo into Northern Rhodesia, Nyasaland, Uganda, Kenya, and Eritrea. The threat to America is principally through air transportation of infected individuals from endemic areas of the world into the gulf coastal United States, which has been classified as a "yellow fever receptive area" because of the large numbers of Aedes aegypti in this area.

South American jungle yellow fever is essentially a disease of jungle animals, especially of monkeys and marsupials. For the most part, the disease in humans is accidental, occurring when humans invade the forests. African jungle yellow fever is primarily a disease of monkeys with several species of Aedes, especially Aedes africanus and Aedes simpsoni, the principal vectors. Should yellow fever become established in urban areas with a high Aedes index, such as exists in the gulf coastal area of the United States, an epidemic could result. Only constant vigilance and control of Aedes can prevent this occurrence.

\section{Typhus}

Murine typhus has been fairly common in the ports and towns bordering the coast. Until the advent of widespread ectoparasite and rat eradication programs, this disease had been spreading to the cities and towns of the interior of the States bordering the coast. Studies are needed on the prevalence of this disease in rat populations. Ectoparasite and rat eradication programs should be continued.

\section{Leptospirosis}

Leptospirosis is primarily a disease of rats, dogs, sheep, goats, cattle, and swine. For many years, it has been known as an occupational disease; today it is recognized as a recreational disease as well. Most cases in humans occur in persons subjected to immersion or wetting with water containing the Spirochaeta or working with, or around, infected animals. Studies of rats in Nashville (11) in 1917; in Washington, D. C. (12) prior to 1918, and in Baltimore (13) in 1924 revealed, respectively, 10, 7, and 10 percent of the rats of these cities to be infected with Leptospira icterohaemorrhagiae. Leptospira pomona infection of dairy cattle and Leptospira canicola infection of dogs have been demonstrated in widespread areas throughout the United States.

\section{Arthropod-Borne Virus Diseases}

Four arthropod-borne virus encephalitides occur in southern States. These are caused by closely related viruses, have birds as their natural reservoirs, and are usually spread by the bite of mosquitoes and ticks. They are eastern and western equine encephalomyelitis, St. Louis encephalitis, and louping ill or encephalomyelitis of sheep. The eastern type of equine encephalomyelitis is confined largely to the east coast of the United States from Louisiana and Florida to Massachusetts. The western type has been reported in nine southern StatesAlabama, Arkansas, Florida, Louisiana, Mississippi, Missouri, Oklahoma, Tennessee, and Texas. Equine encephalomyelitis is the most important infectious disease of horses occurring in the United States at the present time.

\section{Psittacosis}

Psittacosis is annually becoming of greater importance. With increasing frequency, humans are being exposed to infection in pet psittacine birds. The disease, known as ornithosis in chickens and pigeons, will probably be diagnosed more frequently in humans as physicians become more conscious of its occurrence and diagnostic tests become more readily available. Occupational disease, resulting from employment in poultry-processing plants, particularly for turkeys, is being more often recognized. Infection' may follow either fleeting or prolonged exposure.

\section{Salmonellosis}

Infected animals and birds are important sources of the increasing number of Salmonella infections reported in humans. There are probably hundreds of unreported and uninvestigated outbreaks of salmonellosis in the southern States each year. Rarely fatal, the 
disease causes sufficient disability to account for considerable absenteeism. Over 200 salmonellae have been identified. As our knowledge of these organisms has developed, an increasing number have been found to be pathogenic to man. Poultry, swine, cattle, sheep, rodents, dogs, and other animals have been found to harbor salmonellae capable of producing disease in man.

\section{Rabies}

It is a disgrace that rabies, almost a completely preventable disease in domestic animals, is still a threat to humans. From 1946 through $1953,42,144$ cases of animal rabies were reported in the southern States (14). Of the 14 human deaths due to rabies in the United States in 1953, 13 occurred in the southern States. In the past half century more human rabies deaths have occurred in the southern States than in all of the rest of the States combined.

\section{Bovine Mastitis}

Mastitis is a major disease problem in cattle. Because of the resultant drop in milk production subsequent to the disease, it is, economically, probably the most important disease of dairy cattle. Many organisms are capable of causing bovine mastitis but streptococci and staphylococci are the most important. Usually when one animal in a herd is infected the whole herd is soon involved. To be controlled, therefore, mastitis must be attacked as a herd problem.

\section{Brucellosis}

Another major zoonosis affecting cattle and swine which places humans at risk, as well as being extremely costly, is brucellosis. Animals, apparently healthy, will show positive blood agglutination reactions during life, and at death brucellae can be isolated from the tissues of these seemingly healthy animals. Brucellosis is one of the most serious diseases with which the animal industry has to deal. Since the widespread pasteurization of milk for human consumption, brucellosis in humans is largely an occupational disease of farm people, veterinarians, and meat handlers. The economic loss resulting from its ravages runs into millions of dollars annually.
Although human brucellosis is reported each year by State health officers to the National Office of Vital Statistics, the number of reported cases is small in comparison with the number of cases that occur in animals. Few epidemiologists, therefore, attach much significance to reported figures when thinking of incidence and prevalence. Possibly a low index of suspicion of the disease by physicians and the crude diagnostic tests available for confirmation of clinical impressiton contribute to the small number of human cases reported.

\section{Anthrax}

In the period 1945-1951, anthrax attacked 660 herds in the southern States and caused the death of 8,311 animals. Louisiana lost more than half of this number. Only the District of Columbia and West Virginia did not report the occurrence of anthrax during this period. No disease of livestock causes greater consternation and fear than does anthrax when it makes its appearance. It strikes quickly, spreads rapidly, causes heavy losses, and, too often, is transmitted to man. Anthrax in Louisiana Mississippi, and Texas has been recognized since 1860 or earlier (15). In 1953, Arkansas, Florida, Missouri, Oklahoma, Texas, and Virginia accounted for 50 of the 198 laboratoryconfirmed outbreaks of anthrax occurring in the United States.

Louisiana has a particularly difficult problem with anthrax. The disease is endemic there, having been reported from 55 of the 64 parishes (counties). The incidence of human anthrax is relatively high also. Heeren (16) lists 111 cases as being reported from 1920-45. Since 1945 , four cases have been reported.

In June, July, and August 1954, three parishes south of New Orleans-Jefferson, St. Barnard, and Plaquemines-reported a widespread outbreak of anthrax. During this same year, sporadic outbreaks were reported in eight other parishes. About 2,000 animal deaths occurred during this outbreak and 6 human cases were reported. Investigation did not confirm the diagnosis in the reported human cases.

\section{Tuberculosis}

Tuberculosis is a major public health problem because of its transmissibility to many species of 
animals - a fact which persons dealing with human tuberculosis often fail to consider. Feldman says, "The organism of bovine tuberculosis is capable of infecting swine, dogs, cats, parrots, and canaries as well as human beings; the avian tubercle bacillus, besides being pathogenic for most birds, can produce destructive disease in sheep and swine, while the human type of tubercle bacillus is capable of inducing disease in cattle, swine, $\operatorname{dog} \mathrm{s}$, and parrots" (17). According to Feldman few, if any, species of animals, warm- or cold-blooded, have an absolute resistance to the disease.

The United States Department of Agriculture has had a tuberculosis eradication program for about 30 years. At the onset of the program, 5 percent of animals tested were found to be infected. During the fiscal year ending June 30, 1954, more than 10 million (10.8 percent) of the Nation's cattle were tested for tuberculosis (18). The prevalence of bovine tuberculin reactors is now down to 0.1 percent of the animals tested. Today, with bovine tuberculosis, as with human tuberculosis, mass testing gives a very low yield of cases and is extremely costly.

Louisiana is already placing increasing emphasis on good epidemiological investigation of each active case of human tuberculosis, study of suspect contacts, and the application of miss case-finding techniques on a selective basis. 'The livestock industry should continue its mass testing until it can develop adequate epidemiological investigation of each known reactor and diseased animal, and, in the meantime, public health agencies should give the problem careful study. There is a need to identify, locate, and destroy all reactor animals. While this is being done, it must be remembered that healthy animals can be infected with tuberculosis by infected humans. The chain man-toanimal-to-man must always be borne in mind when unexplained reactors occur in a well protected, controlled herd.

\section{Prevalence in Humans}

Except for anthrax and rabies, I have not included figures on incidence and prevalence in humans of diseases originating in animals largely because I am sure each of you is familiar with the human problem in your own locale, and because there is grave doubt of the significance of the low number of reported cases of some of these diseases in humans in view of the widespread occurrence of these same diseases in animals. The prevalence of these diseases among so many animals with which large numbers of our population are in frequent contact emphasizes the threat to human health.

\section{Economic Cost}

The economic impact of the zoonoses is great. I do not know the cost for the southern States as separate from the United States, but the Agricultural Research Service of the United States Department of Agriculture estimates that in the period $1942-51$ the average loss on livestock and poultry from diseases, parasites, and insects amounted to $\$ 2,688$ million per year. The cattle industry is rapidly expanding in the south, particularly in Louisiana, Mississippi, and Georgia. The economy of the southern States is largely agrarian. These facts, when associated with climatic conditions which favor the propagation and spread of parasitic and other diseases of animals, strongly suggest that the southern States are bearing more than their pro rata share of the annual $\$ 2,688$ million livestock and poultry loss.

\section{Control}

Obviously, the zoonoses represent a major public health threat and a serious economic loss to States which can afford neither. It is all very well to talk about the control of brucellosis in humans, for example, through the pasteurization of all milk for human consumption and through the development of laws which would insure safe, wholesome meat. Unfortunately, measures such as these only control and decrease the number of human infections; they do not prevent the disease or eliminate its cost. Our goal should be prevention through attacking and breaking the weak link in the epidemiological chain of infection while continuing to control such diseases as occur before the chain of infection is broken.

To attack this problem properly, mechanics should be developed to assure accurate, early 
reporting of the occurrence of all transmissible diseases in humans and in animals; the establishment of adequate preventive and control measures; the development of a realization of the constant threat of communicable diseases; a higher index of suspicion concerning them, and the development and utilization of better diagnostic and investigational tools and methods by practitioners of medicine, both human and veterinary.

To maintain the gains made in communicable disease control in the south, all groups interested in human and animal health and in our southern economy should join together in sharing attitudes, knowledge, information, skills, methods, and plans for preventing recurrence of the great animal plagues of the past, such as rinderpest, foot-and-mouth disease, fowl pest, Texas fever (bovine piroplasmosis), and bovine tuberculosis, and for controlling the threats of today-rabies, psittacosis, ornithosis, brucellosis, anthrax, plague, and arthropod-borne viral and rickettsial diseases-until they too can be prevented.

\section{Summary}

The transmission of diseases from animal to man and from man to animal poses a serious threat to our health and welfare. Reasonable protective, preventive, and control measures assuring a continually improving public health status and economy will develop to the extent that veterinarians, livestock owners, research workers, economists, physicians, public health officials and others coordinate their efforts and subordinate their personal desires to the development of programs of prevention and control of the zoonoses.

\section{REFERENCES}

(1) Joint WHO/FAO Expert Group on Zoonoses: Report. WHO Technical Report Series No. 40. Geneva, 1951.

(2) Kelser, R. A.: Rabies. In Diseases transmitted from animals to man, edited by T. G. Hull. Ed. 3. Springfield, Ill., Charles C. Thomas, 1947, pp. 179-211.

(3) Williams, R. W.: A check list of the mite vectors and animal reservoirs of tsutsugamushi disease. Aim. J. Trop. Med. 24 : 355-357 (1944).
(4) Blake, F. G., Macy, K. F., Sadusk, J. F., Jr., Kohls, G. M., and Bell, E. J.: Studies on tsutsugamushi disease (scrub typhus, mite borne typhus) in New Guinea and adjacent islands; epidemiology, clinical observations and etiology in Dobadura area. Am. J. Hyg. 41: 243-372 (1945).

(5) Dyer, R. E.: Typhus fever. In Diseases transmitted from animals to man, edited by T. G. Hull. Ed. 3. Springfield, Ill., Charles C. Thomas, 1947, pp. 396-409.

(6) Holle, H. A.: Trypanosomiasis, American (Chagas' disease). Morbidity and Mortality Weekly Report (U. S. National Office of Vital Statistics) $4:$ 2, Dec. 16, 1955.

(y) Griffith, R. L., and McNaughton, D. W.: Report of a case of rat-bite fever due to $S$. moniliformis. Pub. Health Rep. 68: 947-948, October 1953.

(8) Meyer, K. F.: Plague. In Diseases transmitted from animal to man, edited by T. G. Hull. Ed. 3. Springfield, Ill., Charles C. Thomas, 1947.

(9) Carroll, J.: Yellow fever. In Osler's Modern medicine. Philadelphia, Lea Brothers and Co., 1907, vol. 2, pp. 736-759.

(10) Mackie, T. T., Hunter, G. W., and Worth, C. B. : A manual of tropical medicine. Ed. 2. Philadelphia, W. B. Saunders and Co., 1954, pp. 17-18.

(11) Jobling, J. W., and Eggstein, A. A. : The wild rats of the southern States as carriers of Spirachaetae icterohemorrhagiae. J. A. M. A. 69: 1787 (1917).

(12) Neill, M. H.: The problem of acute infectious jaundice in the United States. Pub. Health Rep. 33 : 717-726, May 10, 1918.

(13) Robinson, G. H.: Occurrence of Leptospira icterohemorrhagiae in wild rats of Baltimore. Am. J. Hyg. 4: 327-329 (1927).

(14) Report of the Committee on Rabies. In Proc., U. S. Livestock Sanitary Association, 58th annual meeting, 1954. Trenton, N. J., 1955, pp. 357-362.

(15) Stein, C. D.: Anthrax in livestock in the U. S. and its control. In Proc., U. S. Livestock Sanitary Association, 56th annual meeting, 1952. Trenton, N. J., 1953, pp. 67-86.

(16) Heeren, R. H. : Anthrax in Louisiana. New Orleans Med. \& Surg. J. 99: 545-551, May 1947.

(17) Feldman, W. H.: Tuberculosis. In Diseases transmitted from animal to man, edited by T. G. Hull. Ed. 3. Springfield, Ill., Charles C. Thomas, 1947, pp. 3-58.

(18) Ranney, A. F.: Status of Federal-State cooperative tuberculosis eradication. In Proc., U. $\mathrm{S}$. Livestock Sanitary Association, 58th annual meeting, 1954. Trenton, N. J., 1955, pp. 212217. 